\title{
Disability and Quality of Life among Elderly Persons with Self-Reported Hearing Impairment: Report from the Ibadan Study of Aging
}

\author{
Akeem O. Lasisi ${ }^{1 *}$, Oye Gureje ${ }^{2}$ \\ ${ }^{1}$ Department of Otorhinolaryngology, University of Ibadan, Ibadan, Nigeria \\ ${ }^{2}$ Department of Psychiatry, University of Ibadan, Ibadan, Nigeria \\ Email: ${ }^{*}$ akeemlasisi@gmail.com
}

Received February 6, 2013; revised March 12, 2013; accepted March 21, 2013

\begin{abstract}
Background: Despite a high prevalence of hearing impairment (HI) among the elderly, the effect on their quality of life (QOL) has not been well studied in this environment. Aim: To determine the prevalence of disability and profile of QOL among elderly persons (aged $\geq 65$ years) with HI. Design of Study: Cross-sectional. Setting: Eight contiguousYoruba-speaking states in Nigeria. Methods: Face-to-face interviews of respondents selected using a multi-stage, stratified area probability sampling of households; HI was based on self report and observer confirmation and the QOL was measured with the World Health Organization brief version (WHOQOL-Bref). Results: The prevalence of disability in Activities of Daily Living (ADL) was $35.4 \%$ while it was $10.1 \%$ in Instrumental ADL. Prevalence increased significantly with increasing age $(\mathrm{P}=0.05)$. Disability in ADL $(\mathrm{P}=0.01)$, poor family interaction $(\mathrm{P}=0.01)$, poor community involvement $(\mathrm{P}=0.01)$ cognitive impairment $(\mathrm{P}=0.05)$ and poor report of overall health $(\mathrm{P}=0.05)$ were significantly more common among the elderly with HI than those without. No significant differences were found in regard to current depression or the likelihood of experiencing verbal, physical or emotional abuses. Logistic regression analyses adjusting for age, sex, chronic medical conditions and disability confirmed the salient effect of HI on the decrement in the physical domains $(\mathrm{P}=0.05)$. Conclusion: $\mathrm{HI}$ is associated with high prevalence of disability and has adverse effect on the quality of life. This observation strengthens the need for hearing rehabilitation in the policy formulation on the care of the elderly in resource-poor settings.
\end{abstract}

Keywords: Community Elderly; Hearing Impairment; Disability; Quality of Life; Activity of Daily Living

\section{Introduction}

Increase in life expectancy raises concerns about the cumulative impact of chronic diseases and impairments on role functioning and quality of life among the growing population of older adults. Even though hearing impairments (HI) in elderly people have been associated with a variety of mental conditions and cognitive impairment, [1-4] and has been found to contribute to the additive risk of functional decline in those who have dual sensory impairment [5-8]; the impact of $\mathrm{HI}$ on disability and quality of life remains an under-researched area. In Nigeria, the prevalence of age related hearing loss among the elderly have been documented to be about $6.1 \%$, while up to $60 \%$ have been reported in some other developing countries [9]. In general, empirical evidence of associations between sensory impairment and quality of life and wellbeing is sparse. A better understanding of these relationships could inform efforts to provide more effective in-

${ }^{*}$ Corresponding author. terventions for people with declining hearing [9-11]. The various instruments standardized for the evaluation of quality of life among the elderly include World Health Organization QOL Bref instrument, Short-Form-36 Health Survey (SF-36) among others [1,5,9-11]. In this paper, we examine the association between $\mathrm{HI}$ and functional role impairment and QOL among community-dwelling elderly persons.

\section{Methodology}

\subsection{Patients}

The Ibadan Study of Aging (ISA) is a longitudinal cohort study of the mental and physical health status of elderly persons (aged 65 years and over). The study also evaluates the disability and functional role capacity of the respondents. The study participants reside in the Yorubaspeaking areas of Nigeria, consisting of eight contiguous states in the south-western and north-central regions (Lagos, Ogun, Osun, Oyo, Ondo, Ekiti, Kogi and Kwara). 
These states account for about $22 \%$ of the Nigerian population (approximately, 25 million people). The baseline survey was conducted between November 2003 and August 2004. The methodology has been described in full elsewhere $[12,13]$ and only a brief summary is provided here. Respondents were selected using a multistage stratified area probability sampling of households. In households with more than one eligible person (aged 65 years and fluent in the language of the study, Yoruba), the Kish table selection method was used to select one respondent. Face-to face interviews were carried out at baseline in 2003 on 2149 respondents who provided consent to participate, representing a response rate of $74.2 \%$. An annual three-wave follow-up of the cohort was begun in 2007. Of the baseline sample, 1413 were alive in 2007. This cohort was enlarged by the addition of 461 new respondents, thus resulting in a total of 1874. A second wave assessment was conducted in 2008. A total of 1474 persons $(78.7 \%)$ were successfully interviewed in 2008 . Those who could not be interviewed consisted of 112 $(6.0 \%) 89$ who had died, 275 (14.7\%) who had relocated or could 90 not be found after repeated visits (a maximum of 5 visits 91 were made) and $13(0.7 \%)$ who refused to be interviewed. In the 2008 wave, 1302 provided complete information about hearing and the correlates examined in this report.

The survey was approved by the University of Ibadan/ University College Hospital, Ibadan Joint Ethical Review Board.

\subsection{Measures}

Using standardized protocols administered by trained interviewers, self-report of hearing impairment, among checklist of chronic physical and pain conditions, [14] was obtained in face-to-face assessments.

All respondents were assessed for functional limitations in six activities of daily living (ADL) which included bathing, dressing, toileting, arising and transferring, continence and eating [15] and seven instrumental activities of daily living (IADL) including climbing a flight of stairs, reaching above the head to carry something weighing about $4.5 \mathrm{Kg}$, stooping, gripping small objects with hands, shopping and activities such as sweeping the floor with a broom or cutting the grass [16]. Each of the activities were recorded as 1) do without difficulty; 2) do with some difficulty but without assistance; 3) do with much difficulty, needing some assistance and 4) unable to do. However, in analyzing the data, the ratings were dichotomized as can do independently (1 and 2 above) and can do with assistance, dependent (3 and 4). The former group was regarded a not disabled while the latter was classified as disabled. A subgroup of 37 respondents was assessed twice, about 7 days apart, to assess test-retest reliability of these disability markers. Agreement was generally very good to excellent, with a $\kappa$ range of $0.65-1.0$.

We rated involvement in family and community activities, respectively, as good or poor. Respondents were also asked about the experience of verbal, physical or emotional abuse in the previous year (rated yes or no).

All respondents completed the WHO quality of life instrument, brief version (WHOQOL-Bref) [17]. WHOQOL-Bref was developed as an instrument, applicable across many cultures, for subjective assessment of healthrelated quality-of-life. [15] It was designed in diverse cultural settings, including sub-Saharan Africa [15], and has been validated as a measure of quality of life in elderly people [15]. In our study this instrument had excellent reliability (Cronbach $\dot{\alpha}=0.86$ ). The lower the score on the WHOQOL-Bref, the poorer the quality of life [17].

Depression was assessed using the WHO Composite International Diagnostic Interview, version 3 (CIDI.3), a fully structured diagnostic interview. [18] Diagnosis was based on the criteria of the Diagnostic and Statistical manual of Mental Disorders, fourth edition (DSM-IV) [19]. DSM-IV exclusion rules were imposed for diagnosis of depression.

All instruments were translated with iterative backtranslation method. As part of the translation process, all instruments used underwent cultural adaptation. For example, in describing $4.5 \mathrm{Kg}$ in the functional assessment, a tuber of yam (a local staple food) of equivalent weight was used.

The interviews were done by 24 trained interviewers, all of whom had at least 12 years (high school) education. Many interviewers had previously done field surveys and had experience of face-to-face interviews. Interviewers had a 2-week training, consisting of an initial 6-day training done by one of the authors (OG) (which included item-by-item description of questionnaires and role play), followed by a further 2 days of debriefing and review after every interviewer had done two practice interviews in the field. Six supervisors, all of whom were university graduates and had survey experience, underwent the same level of training and monitored the day-to-day implementation of the survey.

\subsection{Data Analysis}

The unweighted estimates of the occurrence of HI are presented. Demographic and other correlates of $\mathrm{HI}$ are explored with logistic regression analysis. [20] These analyses as well as the estimates of standard errors of the Odds Ratio (OR's) were conducted using the STATA statistical package. [21] The mean scores on the total WHOQOL-Bref as well as on each of its 4 domains were 
compared between elderly persons with $\mathrm{HI}$ and those without and the significance of the difference was determined with a student t-test.

All the confidence intervals (CI) reported were adjusted for design effects. In order to take account of the sample design, the jackknife replication method implemented with the STATA statistical package was applied to estimate standard errors for the means and proportions. Statistical significance was set at 0.05 in two-sided tests.

\section{Result}

The sample consisted of 79 elderly subjects who reported HI out of 1302 surveyed (6.1\%). They are made up of 42 $(53.2 \%)$ females and $37(46.8 \%)$ males. The distribution of the age groups were: $5(6.3 \%)$ in 65 - 69 years range, $12(15.2 \%)$ in $70-74$ years, $19(24.1 \%)$ in the $75-79$ years range and $\geq 80$ years constituted 43 (54.4\%). The median age was 76.2 years.

Impairment in ADL was reported by 28 (35.4\%) of the elderly persons with HI, while $8(10.1 \%)$ were disabled on IADL. Comparing elderly persons with and without HI, increasing age was found to be significantly associated with the prevalence of disability $(\mathrm{P}=0.05)$ while gender difference $(\mathrm{P}=0.85)$ was not.

In comparing the elderly subjects with $\mathrm{HI}$ and those without, disability in ADL $(\mathrm{P}=0.01)$, poor family interaction $(\mathrm{P}=0.01)$, poor community involvement $(\mathrm{P}=$ $0.01)$, poor report of overall health $(\mathrm{P}=0.05)$, and cognitive impairment $(\mathrm{P}=0.05)$ were significantly more common among the elderly with HI than the rest of the population. In contrast, current depression, verbal, physical and emotional abuses were not found to correlate significantly with HI (Table 1).

Elderly subjects with HI and those without were next

Table 1. Univariate analysis of subjects with and without HI.

\begin{tabular}{ccc}
\hline Variable & $\begin{array}{c}\text { Subjects with HI (n=79) vs } \\
\text { those without HI }(\mathrm{n}=1223)\end{array}$ & P value \\
\hline Poor family interaction & $27.9 \%$ vs $13.7 \%$ & 0.01 \\
Poor community involvement & $34.2 \%$ vs $16.6 \%$ & 0.01 \\
IADL & $35.4 \%$ vs $22.2 \%$ & 0.01 \\
Current depression & $10.1 \%$ vs $6.5 \%$ & 0.21 \\
Poor report of overall health & $5.1 \%$ vs $9.7 \%$ & 0.17 \\
Verbal abuse & $82.3 \%$ vs $90.5 \%$ & 0.05 \\
Physical abuse & $1.3 \%$ vs $12.5 \%$ & 0.24 \\
Emotional abuse & $1.3 \%$ vs $0.6 \%$ & 0.42 \\
Cognition & $0.0 \%$ vs $0.8 \%$ & 0.43 \\
\hline
\end{tabular}

compared in regard to quality of life. The overall quality of life $(\mathrm{P}=0.01)$, cognition $(\mathrm{P}=0.02)$, quality of life in the physical $(\mathrm{P}=0.02)$, psychological $(\mathrm{P}=0.01)$, and environmental domains $(\mathrm{P}=0.05)$, were significantly lower among elderly persons with HI (Table 2).

Logistic regression analyses which adjusted for age, sex, chronic medical conditions and presence of disability revealed significantly lower quality of life in the physical domains $(\mathrm{OR}=0.95, \mathrm{P}=0.05,95 \% \mathrm{CI}=95 \%$ $\mathrm{CI}=0.91-1.0)$, less likelihood of engaging with family $(\mathrm{OR}=0.45 ; 95 \% \mathrm{CI}=0.25-0.80 ; \mathrm{P}<0.01$ and community $(\mathrm{OR}=0.40,95 \% \mathrm{CI}=0.22-0.71 ; \mathrm{P}<0.01)$ among the elderly with HI than those without. In contrast, cognitive ability, total quality of life, as well as the environmental, social and psychological domains did not significantly differentiate elderly persons with or without HI.

\section{Discussion}

This study has documented a high prevalence of disability among elderly with self reported HI which increased significantly with age and involved mainly the activities of daily living, family and community interactions. In addition, this study confirmed the significance of $\mathrm{HI}$, as a single morbidity factor, on the decrement in the quality of life in the physical domains of these elderly people. These findings suggest that HI has profound effect on the quality of life of the elderly.

In the work of Cacciatore et al. in Italy in 1996 [1] in which HI was evaluated by questionnaire as in this study, the prevalence rate of disability in ADL was 7.0\%. In contrast, we found a high prevalence of disability, $35 \%$. This may be a reflection of the relative lack of support for the elderly in our community. In addition, Cacciatore et al. [1] and Carabellese et al. in Northern Italy in 1992 [2] found strong relationships between HI and depression and cognitive impairment. The present study did not show any significant association of HI with depression. Even though, we found cognitive impairment to be significant in univariate and multivariate analysis, it was not found to be significant in logistic regression analysis after adjusting for age, gender, disability and other echronic medical illnesses. This suggests that these factors might be confounding factors for cognitive impairment. However, similar to Keller et al. [22] and carabellese et al. [2] our study found significantly higher prevalence of disability in ADL among elderly persons with HI than those without.

Chia et al. [23] reported HI in 31.3\% and found association between HI and poorer SF-36 scores in both physical and mental domains. Similarly, our study found significant impact of HI on the physical and environmental domains of the quality of life among the elderly 
Table 2. Student t-test Analysis of association between mean score of WHOQOL-Bref quality of life and HI.

\begin{tabular}{|c|c|c|c|c|c|c|}
\hline WHOQOL-Bref domain & Group interval & $\mathrm{n}$ & Mean & \multicolumn{2}{|c|}{ [95\% Conf. interval] } & $P$ value \\
\hline \multirow{2}{*}{ Physical } & 0 & 1209 & 24.22 & 23.89 & 24.56 & \multirow{2}{*}{0.01} \\
\hline & 1 & 75 & 21.65 & 20.30 & 23.00 & \\
\hline \multirow{2}{*}{ Psychological } & 0 & 1209 & 21.50 & 21.30 & 21.71 & \multirow{2}{*}{0.02} \\
\hline & 1 & 73 & 20.55 & 19.69 & 21.41 & \\
\hline \multirow{2}{*}{ Environmental } & 0 & 1209 & 9.67 & 9.54 & 9.80 & \multirow{2}{*}{0.05} \\
\hline & 1 & 75 & 9.20 & 8.61 & 9.78 & \\
\hline \multirow{2}{*}{ Social } & 0 & 1204 & 26.79 & 26.54 & 27.03 & \multirow{2}{*}{0.28} \\
\hline & 1 & 74 & 26.49 & 25.48 & 27.50 & \\
\hline \multirow{2}{*}{ QOL-Bref Total } & 0 & 1171 & 82.29 & 81.54 & 83.03 & \multirow{2}{*}{0.01} \\
\hline & 1 & 72 & 78.08 & 74.96 & 81.21 & \\
\hline \multirow{2}{*}{ Cognition } & 0 & 1209 & 3.76 & 3.65 & 3.88 & \multirow{2}{*}{0.02} \\
\hline & 1 & 72 & 3.26 & 2.73 & 3.80 & \\
\hline
\end{tabular}

1-Elderly subjects with $\mathrm{HI} ; 0$ - rest of the population without HI.

in the community. Dalton et al. [10] reported that individuals with hearing loss were more likely than those without hearing loss to have low ADL scores and the severity of hearing loss was significantly associated with decreased physical and mental component summary scores, measured using the Short-Form-36 Health Survey (SF-36). Resnick et al. [24] also reported that HI is associated with low time in activities, while inadequate communication is associated with limits in both social engagement and time in activities. In contrast Bazargan et al. [5] found poor hearing to be associated with a lower level of psychological well-being.

In contrast to our finding, some others did not find evidence of a major effect of hearing acuity on the quality of life of the elderly while others explained the effect to be due to accompanying visual impairment [25-29].

The findings reported here are to be considered in the context of the limitations of the study. The study is significant in that it has shown that occurrence of hearing impairment among the elderly may be indicative of further need for rehabilitative support to help overcome these negative consequences of hearing impairment. This observation strengthens the need for hearing rehabilitation in the policy formulation on the care of the elderly in resource-poor settings. In this study, we used self report and questionnaire assessments. This approach is similar to that of Jagger et al. [29] and others [1-4,7]. Even though self report of hearing impairment is one of the ways of assessing hearing impairment, it might be fraught with a higher probability of under-reporting compared to other methods, such as audiometric assessment of hearing, which provide a more objective assessment of the severity of hearing loss.

In conclusion, this study found that $\mathrm{HI}$ has deleterious effects on functioning and quality of life among the elderly. Our findings suggest the need for active rehabilitation of elderly people with $\mathrm{HI}$ as a way of improving their wellbeing and quality of life.

\section{Acknowledgements}

The Ibadan Study of Aging is funded by the Wellcome Trust. The Wellcome Trust was not involved in the collection analysis or interpretation of data presented in this report.

\section{REFERENCES}

[1] F. Cacciatore, C. Napoli, P. Abete, E. Marciano, M. Triassi and F. Rengo, "Quality of Life Determinants and Hearing Function in An Elderly Population: Osservatorio Geriatrico Campano Study Group," Gerontology, Vol. 45, No. 6, 1999, pp. 323-328. doi:10.1159/000022113

[2] C. Carabellese, I. Appollonio, R. Rozzini, A. Bianchetti, G. B. Frisoni, L. Frattola and M. Trabucchi, "Sensory Impairment and Quality of Life in a Community Elderly Population," Journal of the American Geriatrics Society, Vol. 41, No. 4, 1993, pp. 401-407.

[3] S. Maggi, N. Minicuci, A. Martini, J. Langlois, P. Siviero, M. Pavan and G. Enzi, "Prevalence Rates of Hearing Impairment and Comorbid Conditions in Older People: The Veneto Study," Journal of the American Geriatrics Society, Vol. 46, No. 9, 1998, pp. 1069-1074.

[4] W. J. Strawbridge, M. I. Wallhagen, S. J. Shema and G. A. Kaplan, "Negative Consequences of Hearing Impairment in Old Age: A Longitudinal Analysis," The Gerontologist, Vol. 40, No. 3, 2000, pp. 320-326. doi:10.1093/geront/40.3.320

[5] M. Bazargan, R. S. Baker and S. H. Bazargan, "Sensory Impairments and Subjective Well-Being among Aged African American Persons," The Journals of Gerontology Series B: Psychological Sciences and Social Sciences, Vol. 56, No. 5, 2001, pp. P268-P278. doi:10.1093/geronb/56.5.P268

[6] U. Lindenberger, H. Scherer and P. B. Baltes, "The Strong Connection between Sensory and Cognitive Performance in Old Age: Not Due to Sensory Acuity Reduc- 
tions Operating during Cognitive Assessment," Psychology and Aging, Vol. 6, No. 2, 2001, pp. 96-205.

[7] R. G. LaForge, W. D. Spector and J. Sternberg, "The Relationship of Vision and Hearing Impairment to OneYear Mortality and Functional Decline," Journal of Aging and Health, Vol. 4, No. 1, 1992, pp. 126-148. doi: $10.1177 / 089826439200400108$

[8] M. A. Rudberg, S. E. Furner, J. E. Dunn and C. K. Cassel, "The Relationship of Visual and Hearing Impairments to Disability: An Analysis Using the Longitudinal Study of Aging," Journal of Gerontology, Vol. 8, No. 6, 1993, pp. 261-265. doi:10.1093/geronj/48.6.M261

[9] O. A. Lasisi, T. A. Abiona and O. Gureje, "The Prevalence and Correlates of Self Reported Hearing Impairment from the Ibadan Study of Aging," Transactions of the Royal Society of Tropical Medicine and Hygiene, Vol. 104, No. 8, 2010, pp. 518-523. doi:10.1016/j.trstmh.2010.03.009

[10] D. S. Dalton, K. J. Cruickshanks, B. E. Klein, R. Klein, T. L. Wiley and D. M. Nondahl, "The Impact of Hearing Loss on Quality of Life in Older Adults," Gerontologist, Vol. 43, No. 5, 2003, pp. 661-668. doi:10.1093/geront/43.5.661

[11] J. M. Guralnik, "The Impact of Vision and Hearing Impairments on Health in Old Age," Journal of the American Geriatrics Society, Vol. 47, No. 8, 1999, pp. 10291031.

[12] O. Gureje, A. Ogunniyi, L. Kola and E. Afolabi, "Functional Disability among Elderly Nigerians: Results from the Ibadan Study of Aging," Journal of the American Geriatrics Society, Vol. 54, 2006, pp. 1784-1789.

[13] C. O. Bekibele and O. Gureje, "Self-Reported Visual Impairment and Impact on Vision-Related Activities in an Elderly Nigerian Population: Report from the Ibadan Study of Aging," Ophthalmic Epidemiology, Vol. 92, 2008, pp. 612-615. doi:10.1111/j.1532-5415.2006.00944.x

[14] National Center for Health Statistics, "Evaluation of National Health Interview Survey Diagnostic Reporting," Vital and Health Statistics 2, Vol. 120, 1994, pp. 1-116.

[15] S. Katz, A. B. Ford, R. W. Moskowitz, B. A. Jackson and M. W. Jaffe, "Studies of Illness in the Aged. The Index of ADL: A Standardized Measure of Biological and Psychosocial Function," JAMA, Vol. 185, 1963, pp. 914-919. doi:10.1001/jama.1963.03060120024016

[16] S. Z. Nagi, "An Epidemiology of Disability among Adults in the United States. Milbank Memorial Fund Quarterly," Health Society, Vol. 54, 1976, pp. 439-467.

[17] D. V. Sheehan, K. Harnnet-Sheehan and B. A. Raj, "The Measurement of Disability," International Clinical Psychopharmacology, Vol. 11, Suppl. 3, 1996, pp. 89-95. doi:10.1097/00004850-199606003-00015

[18] The WHOQOL Group, "Development of the World Health Organization Quality of Life Assessment WHOQOL-BREF," Psychological Medicine, Vol. 28, No. 3,
1998, pp. 551-558. doi:10.1017/S0033291798006667

[19] V. J. Naumann and G. J. A. Byrne, "WHOQOL-BREF as a Measure of Quality of Life in Older Patients with Depression," International Psychogeriatrics, Vol. 16, No. 2, 2004, pp. 159-173. doi:10.1017/S1041610204000109

[20] D. W. Hosmer and S. Lemeshow, "Applied Logistic Regression," John Wiley \& Sons, New York, 2000. doi: $10.1002 / 0471722146$

[21] StataCorp, "Stata Statistical Software," Version 7.0 for Windows, Texas, Stata, College Station, 2001.

[22] B. K. Keller, J. L. Morton, V. S. Thomas and J. F. Potter, "The Effect of Visual and Hearing Impairments on Functional Status," Journal of the American Geriatrics Society, Vol. 47, No. 11, 1999, pp. 1319-1325.

[23] E. M. Chia, J. J. Wang, E. Rochtchina, R. R. Cumming, P. Newall and P. Mitchell, "Hearing Impairment and HealthRelated Quality of Life: The Blue Mountains Hearing Study," Ear and Hearing, Vol. 28, No. 2, 2007, pp. 187195. doi:10.1097/AUD.0b013e31803126b6

[24] H. E. Resnick, B. E. Fries and L. M. Verbrugge, "Windows to Their World: The Effect of Sensory Impairments on Social Engagement and Activity Time in Nursing Home Residents," Journals of Gerontology. Series B, Psychological Sciences and Social Sciences, Vol. 52, No. 3, 1997, pp. S135-S144. doi:10.1093/geronb/52B.3.S135

[25] J. J. Wang, R. Lindley, E. Chia, P. Landau, N. Ingham, A. Kifley and P. Mitchell, "Sensory Impairment, Use of Community Support Services and Quality of Life in Aged Care Clients," Journal of Aging and Health, Vol. 19, No. 2, 2007, pp. 229-241. doi:10.1177/0898264307299243

[26] V. Gennis, P. J. Garry, K. Y. Haaland, R. A. Yeo and J. S. Goodwin, "Hearing and Cognition in the Elderly. New Findings and a Review of the Literature," Archives of Internal Medicine, Vol. 151, No. 11, 1991, pp. 2259-2264. doi:10.1001/archinte.1991.00400110105021

[27] Y. Jang, J. A. Mortimer, W. E. Haley, B. J. Small, T. E. Chisolm and A. B. Graves, "The Role of Vision and Hearing in Physical, Social, and Emotional Functioning among Older Adults," Research on Aging, Vol. 25, No. 2, 2003, pp. 172-191. doi:10.1177/0164027502250019

[28] M. Y. Lin, P. R. Gutierrez, K. L. Stone, K. Yaffe, K. E. Ensrud, H. A. Fink, C. A. Sarkisian, A. L. Coleman and C. M. Mangione, "Study of Osteoporotic Fractures Research group. Vision Impairment and Combined Vision and Hearing Impairment Predict Cognitive and Functional Decline in Older Women," Journal of the American Geriatrics Society, Vol. 52, No. 12, 2004, pp. 1996-2002. doi:10.1111/j.1532-5415.2004.52554.x

[29] C. Jagger, N. Spiers and A. Arthur, "The Role of Sensory and Cognitive Function in the Onset of Activity Restriction in Older People," Disability \& Rehabilitation, Vol. 27, No. 5, 2005, pp. 277-283. doi:10.1080/09638280400006523 